\title{
Evaluation of Real Estate Economic Development in Anhui Province Based on Extension Theory
}

\author{
Wen Zhao ${ }^{1, \text { a, * }}$, Qian Wu ${ }^{1, b}$, and Xuetao Wen ${ }^{1, c}$ \\ ${ }^{1}$ School of Civil and Environmental Engineering, Anhui Xinhua University, Anhui 230088, China.

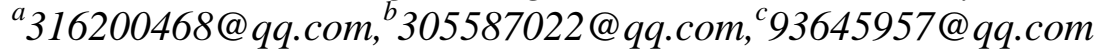

Keywords: sustainable development, objective method of empowerment, degree evaluation.

Abstract: This paper aims to determine the sustainable development ability of the real estate industry in Anhui Province using an index system that is based on extension theory and matter-element theory. Specifically, the paper proposes a comprehensive evaluation model, which is combined with objective empowerment and extension evaluation. Using this model, this paper calculates correlation degrees and weights among the identified factors and presents a comprehensive evaluation of the sustainable development of the real estate markets in 16 cities in Anhui Province.

\section{Introduction}

Anhui Province is located in the East China hinterland and is adjacent to the economically developed Yangtze River Delta. The Province is an important economic hub and has developed industries due to capital and technology transfer [1]. The rapid economic development in Anhui Province can also be attributed to its real estate industry, which plays an important role in the national economy as well. In 2017, real estate development investments in Anhui Province increased from 89.15 billion yuan to 561.25 billion yuan. The sustained development of the real estate industry has a direct impact on the stable development of the national economy.

The so-called "sustainable development" of the real estate industry refers to the industry's ability to meet the needs of various stakeholders and coordinate its development with other industries based on the principles of the appropriate use of resources and environmental protection. Therefore, the development of the real estate industry must prioritize its sustainable development.

Research on the sustainable development of the real estate industry can be divided into two parts. Yue Hongming analyzed the sustainable development ability of the industry from the level of coordination among the industry, the urban environment, social life, and energy consumption pollution [2]. Wang Wei et al. selected indicators from four aspects (price, stock, increment, and development equilibrium) to analyze and study the status of the Xingtai residential real estate market [3]. By analyzing the structure of the real estate development and such factors as commodity housing price, real estate loan financing, and commercial housing vacancy, Wang Xinjun concluded that the regional difference is a limiting factor affecting the sustainable development of the real estate industry in Shandong Province [4]. Wang Xuanhe and Xiao Hongwei collected 18 evaluation indicators from four angles (economy, population, environment, and resources) to analyze the 
sustainable development ability of the real estate market nationwide [5]. Liu Shaotao selected indicators from the perspectives of land resources, economy, and population in Henan Province, in order to provide comprehensive evaluations of the sustainable development of the respective real estate industries in 18 prefecture-level cities in China [6].

In addition, scholars have applied different methods to analyze the ability of the real estate market to develop sustainably. For example, Liu Shaotao [6] used the regression model for analysis. Zeng Guohui used AHP (analytic hierarchy process) to calculate the comprehensive score of each city and then analyzed the sustainable ability of the real estate industry in the cities they studied [7]. Yin and Chu established the efficacy function by selecting the indicators, calculating their evaluation values, and dividing the results into five grades for evaluation [8]. Gui Zhili used data mining techniques, such as quantitative analysis and data smoothing, and also employed the incidence matrix method to evaluate the status of the sustainable development of the real estate industry. [9] Yang Yinghui et al., meanwhile, used factor analysis to evaluate the level of sustainable development of the real estate industry [10].

Based on the past studies using different evaluation indexes, each city and province has its own set of characteristics. From these, we selected and analyzed the common indicators (mainly including economy, population, land resources, and the environment). We then continue our analysis by combining the unique scientific and social characteristics of a city in order to establish our proposed index system. Many past studies have used various methods but most of these do not calculate or measure the indexes. In the present study, we choose the extension evaluation method in designing our proposed model.

\section{Selection of Evaluation Indicators}

The evaluation index system proposed in Table 1 combines different indicators, operational principles, and the results of past studies. We also considered four major aspects (society, economy, environment, resources) to establish the index system and used these to investigate the situation in Anhui Province.

Table 1 The proposed evaluation index system

\begin{tabular}{|c|c|}
\hline Guidelines & Indicators \\
\hline \multirow{3}{*}{$\begin{array}{l}\text { Social evaluation } \\
\text { factor }\end{array}$} & The number of permanent residents $\left(\mathrm{C}_{1}\right)$ \\
\hline & Tap water per capita daily water consumption $\left(\mathrm{C}_{2}\right)$ \\
\hline & GDP per capita $\left(\mathrm{C}_{3}\right)$ \\
\hline \multirow{2}{*}{$\begin{array}{l}\text { Economic evaluation } \\
\text { factor }\end{array}$} & Average wages of real estate employees on the job(c4) \\
\hline & $\begin{array}{c}\text { Real estate development investment accounts for the proportion of fixed } \\
\text { asset investment in the whole societ }\left(\mathrm{C}_{5}\right)\end{array}$ \\
\hline \multirow{4}{*}{$\begin{array}{l}\text { Environmental } \\
\text { assessment factor }\end{array}$} & Green coverage of built-up areas $\left(\mathrm{C}_{6}\right)$ \\
\hline & Per capita park green area $\left(\mathrm{C}_{7}\right)$ \\
\hline & The proportion of days with air quality up to and above grade $2\left(\mathrm{C}_{8}\right)$ \\
\hline & Comprehensive utilization rate of industrial solid waste $\left(\mathrm{C}_{9}\right)$ \\
\hline \multirow{3}{*}{$\begin{array}{l}\text { Resource assessment } \\
\text { factor }\end{array}$} & Total water supply from tap water $\left(\mathrm{C}_{10}\right)$ \\
\hline & Construction area $\left(\mathrm{C}_{11}\right)$ \\
\hline & Building area completion rate $\left(\mathrm{C}_{12}\right)$ \\
\hline \multirow{2}{*}{$\begin{array}{c}\text { Environmental } \\
\text { assessment factors of } \\
\text { science and education } \\
\end{array}$} & The ratio of research and experimental development funds to GDP $\left(\mathrm{C}_{13}\right)$ \\
\hline & Every 100000 people in each city have a college degree or above $\left(\mathrm{C}_{14}\right)$ \\
\hline
\end{tabular}




\section{Establishment of the Matter-Element (ME) Extension Evaluation Model}

The ME analysis method is based on the principle of extentics introduced in 1983. Its main idea is to use "things, characteristics, and values," which are three components used to describe certain things.

3.1 Construction of the ME model to evaluate the sustainable development of the real estate industry

According to the ME analysis method, the following ME model is established:

$$
R_{j}=\left[\begin{array}{ccc}
N_{j} & c_{1} & v_{j 1} \\
& \vdots & \vdots \\
& c_{i} & v_{j i} \\
& \vdots & \vdots \\
& c_{n} & v_{j n}
\end{array}\right] .
$$

In the equation above, $R_{j}$ refers to the sustainable development ability and material element, $N_{j}$ refers to the evaluation factor, $C_{i}$ represents the characteristics of the evaluation factors, and $v_{j i}$ refers to the value of the evaluation factor in terms of its characteristics.

\subsection{Determination of the measurement conditions}

To evaluate real estate industry's sustainable development ability, the measurement conditions must be determined according to the established evaluation index system set as $T=\left\{T_{1}, T_{2}, \cdots T_{i}, \cdots T_{n}\right\}$. We also need to determine the measure conditions. The characteristic of the yuan is given by $T_{i}=\left(c_{i}, v_{i}\right)$, and $v_{i}$ is the quantification of the domain.

\subsection{Establishment of the correlation function, calculation, and normalization}

In the measurement condition $T=\left\{T_{1}, T_{2}, \cdots T_{i}, \cdots T_{n}\right\}, T_{i}=\left(c_{i}, v_{i}\right)$, we establish the correlation function given by [11][12].

$$
k_{i j}=\left\{\begin{array}{l}
\frac{\rho\left(x_{i}, v_{i j}\right)}{\left|v i_{j}\right|}, x_{i} \in V_{i j} \\
\frac{\rho\left(x_{i}, V_{i j}\right)}{D\left(x_{i}, v i_{j}, V_{i}\right)}, x_{i} \notin V_{i j}
\end{array}\right.
$$

Where $\left|v_{i j}\right|$ represents the magnitude of $v_{i j}, \rho\left(x_{i}, v_{i j}\right)$ is the distance between $x_{i}$ and $v_{i j}$, and $D=\left(x_{i}, v_{i j}, v_{i}\right)=\rho\left(x_{i}, v_{i}\right)-\rho\left(x_{i}, v_{i j}\right)$ is the bit value of $x_{i}$ in relation to the interval set $v_{i j}$ and $v_{i}$ $(i=1,2, \cdots n ; j=1,2, \cdots m)$. The qualification of each measurement condition is obtained as

$$
K\left(N_{j}\right)=\left[\begin{array}{c}
k_{1 j} \\
k_{2 j} \\
\vdots \\
k_{n j}
\end{array}\right] \quad(\mathrm{j}=1,2, \ldots, \mathrm{m})
$$




\subsection{Objective weighting method to determine weight}

In determining the weight, we consider the fact that the subjective weighting method can greatly influence the weight. In comparison, the objective weighting method eliminates the influence of subjective factors on the weight. The main examples of the objective weighting method include principal component analysis, entropy value method, and deviation method. The calculation of feature weights described below uses the method of correlation degree deviation [8].

First, we calculate the mean of all categories of correlation degree as follows:

$$
\overline{k_{i j}}=\frac{1}{m} \sum_{j=1}^{m} k_{i j} .
$$

Then, we calculate the deviation by using the following equation:

$$
k_{i}=\sum_{j=1}^{m}\left(k_{i j}-{\overline{k_{i}}}^{2}\right. \text {. }
$$

Finally, each weight is obtained as follows:

$$
\alpha=\frac{k_{i}}{\sum k_{i}}
$$

\subsection{Calculate the extension}

The optimization calculation formula of object $N_{j}$ is:

$$
C\left(N_{j}\right)=\alpha K\left(N_{j}\right)=\left(\alpha_{1}, \alpha_{2}, \cdots \alpha_{n}\right)\left[\begin{array}{c}
k_{1 j} \\
k_{2 j} \\
\vdots \\
k_{n j}
\end{array}\right] .
$$

After calculating and comparing the values for all regions, we obtain the strength of the sustainable development ability of the real estate industry in each region.

\section{Application Analysis}

Based on the 2017 Anhui Statistical Yearbook, the selected indicators are shown in Table 1. The table features a total of 14 indicators obtained as follows: $C_{i}, i=1,2, \cdots, 14$, and $v_{1}, v_{2}, \cdots v_{16}$ respectively represent the following cities: Hefei, Huaibei, Bozhou, Suzhou, Lu'an, Huainan, Chuzhou, Bengbu, Fuyang, Maanshan, Wuhu, Xuancheng, Tongling, Chizhou, Anqing, and Huangshan.

\subsection{Building the ME model of the sustainable development of the real estate industry}

First, we took the 2017 data of the cities' evaluation factor indexes indicating the sustainable development abilities of their real estate industries as $a_{i}$. Then, we set the maximum value of each index in 2017 as the target value $b_{i}$, after which we construct the classical domain $\left\langle a_{i}, b_{i}\right\rangle$ and establish the 14-dimensional ME model as follows: 


$$
R=(N, C, V)=\left[\begin{array}{ccc}
N, & c_{1}, & <a_{1}, b_{1}> \\
& c_{2} & <a_{2}, b_{2}> \\
\vdots & \vdots \\
& c_{14} & <a_{14}, b_{14}>
\end{array}\right] .
$$

\subsection{Calculation of the correlation degree}

Here, $\mathrm{K}_{\mathrm{ij}}$ refers to the correlation degree, which is calculated respectively from the above calculation formula of correlation degree. The calculation results are shown in Table 2.

Table 2 Results of the correlation degree calculation

\begin{tabular}{|c|c|c|c|c|c|c|c|c|}
\hline $\begin{array}{c}\mathrm{K}_{\mathrm{ij}} \\
\text { City }\end{array}$ & $\mathrm{V}_{1}$ & $\mathrm{~V}_{2}$ & $\mathrm{~V}_{3}$ & $\mathrm{~V}_{4}$ & $\mathrm{~V}_{5}$ & $\mathrm{~V}_{6}$ & $V_{7}$ & $\mathrm{~V}_{8}$ \\
\hline $\mathrm{C}_{1}$ & 0.000 & -0.128 & -0.426 & -0.350 & -0.301 & 0.019 & -0.320 & -0.411 \\
\hline $\mathrm{C}_{2}$ & -0.171 & -0.017 & -0.021 & 0.000 & -0.214 & -0.027 & -0.368 & -0.301 \\
\hline $\mathrm{C}_{3}$ & 0.000 & -0.301 & -0.048 & -0.106 & -0.387 & 0.000 & -0.166 & -0.283 \\
\hline $\mathrm{C}_{4}$ & -0.317 & 0.000 & -0.130 & -0.357 & -0.460 & -0.228 & -0.218 & 0.000 \\
\hline $\mathrm{C}_{5}$ & -0.329 & -0.023 & -0.003 & -0.459 & -0.184 & 0.036 & -0.206 & -0.388 \\
\hline $\mathrm{C}_{6}$ & -0.426 & -0.301 & 0.000 & -0.499 & -0.276 & -0.150 & -0.342 & -0.401 \\
\hline $\mathrm{C}_{7}$ & -0.178 & -0.187 & -0.156 & -0.160 & -0.085 & -0.266 & 0.000 & -0.371 \\
\hline $\mathrm{C}_{8}$ & -0.187 & -0.101 & -0.236 & 0.000 & -0.150 & -0.110 & -0.354 & -0.092 \\
\hline $\mathrm{C}_{9}$ & -0.416 & -0.024 & -0.003 & -0.171 & 0.019 & -0.213 & -0.359 & -0.350 \\
\hline $\mathrm{C}_{10}$ & -0.499 & -0.024 & -0.025 & -0.018 & -0.156 & -0.053 & 0.000 & -0.036 \\
\hline $\mathrm{C}_{11}$ & 0.000 & -0.116 & -0.390 & -0.219 & -0.289 & -0.052 & -0.255 & -0.061 \\
\hline $\mathrm{C}_{12}$ & -0.474 & -0.315 & -0.159 & -0.021 & -0.356 & -0.210 & -0.372 & -0.480 \\
\hline $\mathrm{C}_{13}$ & -0.002 & -0.038 & -0.039 & -0.036 & -0.230 & -0.097 & 0.888 & -0.080 \\
\hline $\mathrm{C}_{14}$ & 0.000 & -0.470 & 0.000 & -0.081 & -0.405 & -0.099 & -0.296 & -0.363 \\
\hline $\begin{array}{c}\mathrm{K}_{\mathrm{ij}} \\
\text { City }\end{array}$ & $\mathrm{V}_{9}$ & $\mathrm{~V}_{10}$ & $\mathrm{~V}_{11}$ & $\mathrm{~V}_{12}$ & $\mathrm{~V}_{13}$ & $\mathrm{~V}_{14}$ & $\mathrm{~V}_{15}$ & $\mathrm{~V}_{16}$ \\
\hline $\mathrm{C}_{1}$ & -0.477 & -0.138 & -0.353 & -0.188 & -0.034 & -0.010 & -0.498 & 0.000 \\
\hline $\mathrm{C}_{2}$ & -0.243 & 0.000 & -0.498 & -0.292 & -0.451 & -0.419 & -0.284 & -0.122 \\
\hline $\mathrm{C}_{3}$ & -0.091 & -0.229 & -0.103 & -0.370 & -0.323 & -0.372 & -0.250 & -0.388 \\
\hline $\mathrm{C}_{4}$ & -0.075 & 0.158 & -0.496 & -0.430 & -0.013 & -0.404 & -0.159 & -0.496 \\
\hline $\mathrm{C}_{5}$ & -0.259 & -0.081 & -0.253 & -0.200 & -0.035 & -0.199 & -0.002 & -0.456 \\
\hline $\mathrm{C}_{6}$ & -0.399 & -0.376 & -0.324 & -0.402 & 0.000 & -0.459 & -0.461 & -0.156 \\
\hline $\mathrm{C}_{7}$ & -0.442 & -0.469 & -0.162 & -0.296 & 0.000 & -0.116 & -0.268 & -0.450 \\
\hline $\mathrm{C}_{8}$ & -0.458 & -0.337 & -0.490 & -0.452 & -0.424 & -0.481 & -0.311 & 0.000 \\
\hline $\mathrm{C}_{9}$ & 0.000 & -0.110 & -0.100 & -0.352 & -0.087 & -0.157 & 0.000 & -0.311 \\
\hline $\mathrm{C}_{10}$ & -0.033 & -0.101 & -0.171 & -0.002 & -0.046 & 0.000 & -0.064 & -0.013 \\
\hline $\mathrm{C}_{11}$ & -0.187 & -0.144 & -0.386 & -0.354 & -0.064 & -0.087 & -0.363 & 0.000 \\
\hline $\mathrm{C}_{12}$ & -0.483 & 0.000 & -0.181 & 0.000 & -0.112 & -0.351 & -0.335 & -0.113 \\
\hline $\mathrm{C}_{13}$ & -0.188 & -0.164 & -0.273 & -0.017 & -0.076 & -0.006 & -0.096 & -0.036 \\
\hline $\mathrm{C}_{14}$ & -0.218 & -0.469 & -0.334 & -0.305 & -0.459 & -0.386 & -0.464 & -0.477 \\
\hline
\end{tabular}




\subsection{Calculation of the characteristic weight}

We used the correlation deviation method to calculate weight characteristics. The results of our calculation are shown in Table 3. The table indicates the two indexes that were weighted, namely, $\mathrm{R} \& \mathrm{D}$ spending as a proportion of GDP and real estate on-the-job worker average wage. We can also see the larger impact on the real estate sustainable development ability of these indexes.

Table 3 Results of the calculation of the characteristic weights

\begin{tabular}{c|ccccccc}
\hline $\begin{array}{c}\text { Evaluation } \\
\text { index }\end{array}$ & C1 & C2 & C3 & C4 & C5 & C6 & C7 \\
\hline Weight & 0.085 & 0.07 & 0.048 & 0.102 & 0.064 & 0.059 & 0.055 \\
\hline $\begin{array}{c}\text { Evaluation } \\
\text { index }\end{array}$ & C8 & C9 & C10 & C11 & C12 & C13 & C14 \\
\hline Weight & 0.073 & 0.055 & 0.037 & 0.047 & 0.07 & 0.162 & 0.071 \\
\hline
\end{tabular}

\subsection{Optimization calculation}

Based on the calculation results in Table 2 and Table 3, the extensibility of each city is calculated according to the formula. The calculation results are shown in Table 5.

Table 4 Results of the optimization calculation

\begin{tabular}{c|cccccccc}
\hline City & V1 & V2 & V3 & V4 & V5 & V6 & V7 & V8 \\
\hline C(Nj) & -0.1887 & -0.1327 & -0.1162 & -0.1721 & -0.2590 & -0.1064 & -0.0772 & -0.2409 \\
\hline City & V9 & V10 & V11 & V12 & V13 & V14 & V15 & V16 \\
\hline C(Nj) & -0.2571 & -0.1609 & -0.3109 & -0.2444 & -0.1466 & -0.2364 & -0.2466 & -0.1061 \\
\hline
\end{tabular}

According to the size of the extension in various cities, we are able to determine the pros and cons of the 16 cities. As can be seen from the table, the sustainable abilities of the cities of Wuhu, Bengbu, and Lu'an are the highest, whereas that of Hefei is lower than the those of the three cities.

\section{Conclusion}

In this paper, we establish a real estate index system to evaluate the sustainable development ability of cities in Anhui Province. We conducted qualitative and quantitative analyses on the sustainable development ability of the real estate industries in 16 cities. The results indicated that the sustainable development ability of Hefei City is at the lower half of the list. Therefore, the local government and the local real estate industry should focus on improving the City's ability to achieve its retail industry's sustainable development ability. Both sectors should implement strategies so as to promote the healthy development of this industry.

\section{Acknowledgements}

This work was financially supported by the Anhui Education Department Provincial Quality Project (Grant: 2016tszy042).

\section{References}

[1] Zhang Shujun. A Comprehensive Evaluation Study on Sustainable Development of Real Estate Industry in Anhui 
Province Based on Pprincipal Component Analysis. Anhui University of Architecture, 2017: 1.

[2] Yue Hongming, Changsha City Real Estate Evaluation of Sustainable Development, Hunan Normal University, 2014:34-39.

[3] Wang Wei, Sun Yongzhen, Huang Weijing, Research on the Health of Xingtai Real Estate Industry -- based on the Housing Market. Hebei Enterprises, 2018(04):74-75.

[4] Wang Xinjun. A Study on Sustainable Development of Real Estate Industry in Shandong Province. Shandong Normal University, 2014:28.

[5] Wang Xuanhe, Xiao Hongwei. Research on Chinese Real Estate Sustainable Development Model. Hainan Finance, 2013(02):12-15.

[6] Liu Shaotao, Research on Sustainable Development of Real Estate Industry in Henan Province. Science and Technology Entrepreneurship Monthly, 2012, 25(09):32-33.

[7] Zeng Guohui. Empirical Research on Real Estate's Healthy Development System--a Case from Jiangxi Province, Nanchang: Jiangxi Normal University, 2012:25-29.

[8] Yin Ziming, Chu Mingchang, Empirical Analysis and Research on Sustainable Development of Urban Real Estate Industry.China Management Informatization, 2007(11):31-32

[9] Li Guizhi, Yang Huiyun, Data mining and Evaluation of Sustainable Development of Real Estate Industry in third-tier Cities, Journal of Education College, Kaifeng,2017,37(07):248-249.

[10] Yang Yinghui, Wu Hao, Zhou Hang, Evaluation of Sustainable Development Degree for Real Estate Based on Factor Analysis, Practice and Understanding of Mathematics, 2012,42(15): 92-99.

[11] Cai Wen, Yang Chunyan, Lin Weichu. Extension Engineering Methods [M]. Beijing: Science Press, 2000:1-17.

[12] Cai Wen. Overview of Extenics, Systems Engineering Theory and Practice, 1998, 18 (1): 76-83. 